\title{
CORRESPONDENCE
}

cooperation between Health and Home Affairs ministries, with the former providing the medical manpower, the latter the facilities. There is no Hospital Order in Singapore and indeed the Judiciary would argue that there is no need for it.

I agree with Ruth McCutcheon about overseas training experience at senior registrar level (a point to consider for the future specialist registrar grade). Plachaud (1992) suggests forging links with a view to establishing a list of approved overseas centres for the purpose of higher psychiatric training. The recent establishment of the Institute of Mental Health in Singapore heralds an important move towards more research and development; the service would certainly welcome a partnership in this endeavour.

As a possible training centre, Singapore offers a unique blend of East and West, continues to use English as the first language, and has highly advanced information technology. The logical first step would be an exchange exercise in the subspecialities and I invite the Joint Committee of Higher Psychiatric Training (JCHPT) to consider this.

PIACHAUD J. (1992) Overseas doctors-training ethos. (Letter). Psychiatric Bulletin, 16, 666.

Robertson, J. R., HALSTEAD, S., TAN, T \& LAWRENCE, J. (1992) Psychiatric training, Singapore. Psychiatric Bulletin, 16, 36-38.

JeYaBala BaLAKRISHNA, St George's Hospital, London SW17 OGT

Sir: Dr Balakrishna supports the value of overseas training experience for higher psychiatric trainees and suggests a two-way exchange.

The approval of higher training overseas is not entirely straightforward, since there is no exact equivalent in other countries of this grade, with its expectations of training and supervision rather than purely service. In many countries also the differentiation of psychiatry into six specialities (general adult psychiatry, old age, child and adolescent psychiatry, psychotherapy, forensic, mental handicap) is not as well developed as in the UK. However the JCHPT recognises the value of overseas experience and one year of the minimum three year higher training period spent overseas can be approved for higher training. Because of the differences in training and the impracticality of inspecting overseas placements, this is currently required to be by outposting and approval from a higher training scheme in this country. Similar recognition will apply to higher training in the new specialist registrar grade.

The JCHPT is also exploring, with the College, a pilot scheme to enable overseas psychiatrists to come to this country for higher training.

E. S. PAYKEL, Chairman, Joint Committee on Higher Psychiatric Training, Royal College of Psychiatrists

\section{Lithium prescribing and monitoring in general practice}

Sir: The letter from Dr A. D. Armond (Psychiatric Bulletin, February 1995, 19, 117) concerning lithium prescribing and monitoring in general practice has been widely reported in the general practice press; the views expressed on management cannot pass unchallenged. Dr Armond suggests that lithium prophylaxis should not take place in general practice even when the patient is stabilised, and that the complex pharmacology of lithium and the variability of supervision make general practitioners (GPs) unsuitable to administer this drug. This view correlates with the perception among some psychiatrists that GPs are "particularly liable to make inappropriate choice of drug and dose" (Brown, 1993).

It is unusual for a GP to initiate treatment with lithium. Those patients with severe affective symptoms requiring lithium will not have responded adequately to neuroleptic or antidepressant treatment. The help of a psychiatrist is then often needed. Some patients, however, refuse to see a psychiatrist because of perceived stigma associated with a psychiatric referral. Therefore, I have started some patients on lithium for its mood stabilising effects, and also as adjunctive treatment for depression. Dr Armond's anxieties about the interaction between lithium and other drugs has been largely obviated by the development of computer programmes in general practice which will warn the doctor, at the time of prescribing. about possible interactions.

Lithium undoubtedly needs to be monitored carefully within the community. Psychiatrists may not be aware that the trend for monitoring chronic disease is to involve primary care where possible, and there are drugs of equal 